\title{
Sobre o primeiro fundamento da distinção de direções no espaço' ${ }^{1}$
}

\author{
[Von dem ersten Grunde des Unterschiedes der Gegenden im Raume]
}

\section{Tradução de Rogério Passos Severo}

/377/ O célebre Leibniz teve muitos conhecimentos efetivos com os quais enriqueceu as ciências, mas tinha ainda projetos muito maiores, cuja execução o mundo esperou dele em vão. ${ }^{2}$ Não quero aqui decidir se a causa disto reside no fato de que, para ele, suas tentativas ainda parecessem demasiado incompletas - uma escrupulosidade própria de homens de mérito e que privou a erudição de todos os tempos de fragmentos muito valiosos -, ou se com ele ocorreu o que Boerhaave ${ }^{3}$ conjectura sobre os grandes químicos, que freqüentemente alegavam poder obter produtos como se estivessem na posse dos mesmos, quando, na verdade, estavam apenas persuadidos e confiantes em sua habilidade técnica para produzi-los, e cuja execução não poderia falhar, caso quisessem empreendê-las. Pelo menos, parece que uma certa disciplina matemática, que ele antecipadamente intitulou de analysis situs, ${ }^{4}$ e cuja perda Buffon, ${ }^{5}$ entre outros, lamentou ao considerar as pregas naturais nos embriões, ${ }^{6}$ nunca foi nada além de uma quimera. Não sei ao certo em que medida o objeto que aqui me proponho a considerar tem parentesco com o que o grande homem mencionado tinha em mente; a julgar apenas pelo significado das palavras, procuro aqui filosoficamente o primeiro fundamento da possibilidade daquilo cujas grandezas ele tencionara determinar matematicamente. ${ }^{7}$ Pois as posições das partes do espaço nas suas relações recíprocas pressupõem a direção para a qual estão ordenadas em tal relação, e, num entendimento mais abstrato, a direção não consiste na relação de uma coisa no espaço com outra - o que é propriamente o conceito de posição -, mas na relação do sistema dessas posições com o espaço universal absoluto. ${ }^{8}$ Em tudo que seja extenso, a posição de suas partes umas em relação às outras pode ser conhecida suficientemente pela consideração da própria coisa extensa; mas a direção para a qual essa ordenação das partes está orientada refere-se ao espaço fora dela, e na verdade $/ 378$ / não aos seus lugares, pois isso nada mais seria do que a posição das partes mesmas em uma relação externa, mas sim ao espaço universal como uma unidade, do qual cada extensão tem de ser vista como uma parte. Não seria estranho se o leitor achasse ainda muito incompreensíveis esses conceitos que, antes de mais nada, também devem ser esclarecidos no que se segue. Por isso, não acrescento mais nada, senão que meu fim nesta dissertação seria o de investigar se nos juízos intuitivos da extensão, como os que a geometria contém, não se encontraria uma prova evidente de que o espaço absoluto, 
independentemente da existência de toda matéria e inclusive como primeiro fundamento da possibilidade de sua composição, tenha uma realidade própria. Todo mundo sabe como foram inúteis os esforços dos filósofos no sentido de colocar de vez este ponto fora de qualquer disputa mediante os juízos mais abstratos da metafísica, e não conheço nenhuma tentativa de realizar isso como que a posteriori (a saber, mediante outras proposições irrefutáveis, que na verdade se encontram elas mesmas fora do domínio da metafísica, mas podem fornecer por seu emprego in concreto, uma pedra de toque de sua correção), a não ser a dissertação do célebre Euler, o velho, [publicada] na História da Academia Real de Ciências de Berlim, de $1748,{ }^{9}$ que, contudo, não alcançou completamente seu fim, pois apenas mostra as dificuldades de se dar um significado determinado às leis mais gerais do movimento, se não se aceita nenhum outro conceito de espaço a não ser aquele que resulta da abstração da relação entre coisas existentes, deixando intactas, contudo, as não menores dificuldades que permanecem quando da aplicação das leis em questão, se se quer representá-las in concreto segundo o conceito de espaço absoluto. A prova que aqui procuro deve fornecer não aos mecânicos, como o Senhor Euler tinha em vista, mas aos próprios geômetras uma razão convincente para que possam afirmar, com sua evidência habitual, a realidade do seu espaço absoluto. Para isso, apresento as seguintes preliminares.

No espaço corpóreo, por causa de suas três dimensões, deixam-se pensar três planos, que se entrecortam todos em ângulos retos. Uma vez que conhecemos, por meio dos sentidos, tudo o que está fora de nós somente à medida que se encontre em relação conosco, não é de estranhar que para gerar o primeiro fundamento do conceito de direções no espaço, partamos da relação destes planos de interseção com nosso corpo. /379/ O plano perpendicular ao comprimento de nosso corpo chama-se, em relação a nós, horizontal; e esse plano horizontal dá ensejo à distinção das direções que designamos por acima e abaixo. Sobre esse plano podem estar dois outros, perpendiculares e cruzando-se igualmente em ângulos retos, de modo que o comprimento do corpo humano é pensado na linha de interseção. Um desses planos verticais divide o corpo em duas metades exteriormente similares e dá o fundamento da distinção entre o lado direito e o esquerdo; o outro, que the é perpendicular, faz com que possamos ter o conceito de lado de frente e de trás. Em uma folha escrita, por exemplo, distinguimos primeiro o lado de cima do de baixo da escrita, observamos a distinção dos lados frente e verso, e então vemos a posição da letra da esquerda para a direita ou ao contrário. Aqui, a posição reciproca das partes ordenadas sobre a superfície é sempre a mesma e se constitui em uma figura inteiramente idêntica, podendo-se virar a folha como se quiser; mas a distinção das direções tem tanta importância nesta representação e está tão estreitamente ligada à impressão que o objeto visível produz, que a mesma escrita torna-se irreconhecível quando vista de tal modo que seja volvido da direita para a esquerda tudo o que antes tomava a direção contrária. 
Mesmo nossos juízos sobre os pontos cardeais são subordinados ao conceito que temos de direções em geral, à medida que são determinados com relação aos lados do nosso corpo. As demais relações que conhecemos no céu e na terra independentemente desses conceitos fundamentais são apenas posições dos objetos entre si. Por melhor que eu também conheça a ordem dos quadrantes do horizonte, só poderei determinar as direções por meio disso se estiver consciente da mão a partir da qual essa ordem segue; e o planisfério mais preciso, por mais precisamente também que o tivesse em meu pensamento, não me colocaria em condição de saber, a partir de uma direção conhecida, do norte, por exemplo, de que lado do horizonte teria de procurar o nascer do sol, se a direção não fosse determinada não apenas pela posição das estrelas entre si, mas também pela situação do diagrama em relação às minhas mãos. ${ }^{10} \mathrm{O}$ mesmo ocorre com o conhecimento geográfico $\mathrm{e}$ também com o nosso conhecimento mais comum da posição dos lugares, que em nada nos ajuda, se não podemos colocar as coisas desse modo ordenadas e o sistema todo das $/ 380$ / posições recíprocas em uma relação com os lados de nosso corpo de acordo com as direções. Existe até mesmo uma característica muito notável nos seres vivos, que ocasionalmente pode até dar ensejo a diferenças de espécies, consistente na direção determinada para a qual a ordem de suas partes está voltada e pela qual podem-se diferenciar duas criaturas, ainda que coincidam inteiramente tanto no que diz respeito ao tamanho quanto também na proporção e até mesmo na posição recíproca das partes. Os cabelos no alto da cabeça de todos os homens são voltados da esquerda para a direita. Todo lúpulo enrosca-se da esquerda para a direita em sua rama; já o feijão volta-se no sentido contrário. Quase todos os caracóis, exceto apenas umas três espécies, têm sua torção da esquerda para a direita quando se olha de cima, isto é, da cúspide à boca." Essa qualidade determinada reside invariavelmente nessas mesmas espécies de criaturas, sem relação alguma com o hemisfério onde as mesmas se encontram, nem com a orientação da rotação diária do sol e da lua, que para nós vai da esquerda para a direita, mas para nossos antípodas vai [no sentido] contrário; pois nos produtos naturais mencionados, a causa da circunvolução repousa na própria semente. Por outro lado, onde uma certa rotação pode ser atribuída ao curso desses corpos celestes - como a lei que Mariotte $^{12}$ pretende ter observado em relação aos ventos, que percorreriam de boa mente toda a bússola, do alvorecer ao meio-dia, da esquerda para a direita - aí este movimento circular tem de proceder no sentido inverso no outro hemisfério, como também Don Ulloa ${ }^{13}$ pensa ter efetivamente confirmado por meio de suas observações sobre os mares do sul.

Visto que o sentimento diverso dos lados direito e esquerdo é de tão grande necessidade para o juízo de direções, a natureza conectou-o simultaneamente com o arranjo mecânico do corpo humano, por meio do qual um dos lados, a saber, o direito, tem uma vantagem indubitável em agilidade e talvez também em força sobre o esquerdo. Eis porque todos os povos da Terra são destros (se se desconsidera 
exceções isoladas, as quais, como a do estrabismo, não podem revogar a universalidade da regra de acordo com a ordem natural). É mais fácil mover o corpo da direita para a esquerda do que ao contrário quando se monta o cavalo ou se atravessa um fosso. Escreve-se, por toda a parte, com a mão direita, e com ela $1381 /$ se faz tudo aquilo para o que é requerido habilidade e força. Porém, assim como o lado direito parece ter vantagem sobre o esquerdo no que diz respeito à mobilidade, o esquerdo a tem sobre o direito no tocante à sensibilidade, se nos for permitido acreditar em alguns naturalistas, como por exemplo Borelli ${ }^{14} \mathrm{e}^{\text {Bonnet }}{ }^{15}$, o primeiro dos quais afirma a respeito do olho esquerdo, o segundo também do ouvido esquerdo, que neles o sentido é mais forte do que nos instrumentos homônimos do lado direito. E assim, os dois lados do corpo humano, apesar de sua grande similaridade exterior, são suficientemente distinguidos por uma sensação clara, mesmo que se desconsidere igualmente as posições diferentes das partes internas e a batida perceptível do coração, quando este músculo, a cada contração, bate do lado esquerdo do peito com sua extremidade em movimento oblíquo.

Queremos, portanto, provar que o fundamento de determinação completo de uma forma corpórea não depende meramente da relação e da posição de suas partes umas com as outras, mas, além disso, de uma relação com o espaço absoluto universal, como o que os geômetras pensam, ainda que, entretanto, não se possa perceber imediatamente esta relação, mas sim, contudo, aquelas diferenças entre corpos que dependem única e exclusivamente desse fundamento. Se duas figuras, desenhadas sobre um plano, são iguais e similare $^{16}$ entre si, então elas recobremse mutuamente. Todavia, com a extensão corpórea, e também com as linhas e superfícies que não se encontram em um plano, as coisas passam-se freqüentemente de modo bem diverso. Elas podem ser completamente iguais e similares e, contudo, ser em si mesmas tão diferentes que os limites de uma não podem ser simultaneamente os limites da outra. Um parafuso cuja rosca procede da esquerda para a direita nunca servirá a uma porca cuja rosca vai da direita para a esquerda, mesmo que sua espessura e o número de voltas do parafuso fossem iguais na mesma altura. Um triângulo esférico pode ser completamente igual e similar a outro, sem entretanto recobri-lo. Temos, porém, o exemplo mais comum e claro [disso] nos membros do corpo humano, que são ordenados simetricamente no plano vertical do mesmo. A mão direita é similar e igual à esquerda, e se olharmos apenas para uma delas isoladamente, para a proporção e posição recíproca das partes e para a grandeza do todo, uma descrição completa de uma também tem de valer inteiramente para a outra.

/382/ Designo um corpo completamente igual e similar a outro, e que mesmo assim não pode ser incluído nos mesmos limites, de sua contrapartida incongruente.$^{17}$ Para mostrar então sua possibilidade, tome-se um corpo que não seja composto de duas metades ordenadas simetricamente de acordo com um plano de interseção único, como uma mão humana. Baixem-se de todos os pontos de sua 
superfície linhas perpendiculares a um quadro colocado em frente, e prolonguemse as linhas do mesmo modo para trás numa distância equivalente à que há entre os pontos e o quadro; desse modo, os pontos finais da linha assim prolongada constituem (se forem ligados) a superfície de uma forma corpórea que é a contrapartida incongruente da precedente; isto é, se a mão dada é direita, então sua contrapartida é uma [mão] esquerda. A imagem de um objeto no espelho baseia-se nos mesmos fundamentos. Pois o objeto aparece sempre atrás do espelho na mesma distância em que se encontra diante dele, e por isso a imagem de uma mão direita nele sempre ser a de uma [mão] esquerda. Se o próprio objeto é composto de duas contrapartidas incongruentes, como o corpo humano, quando se o divide por meio de um corte vertical de frente para trás, então sua imagem lhe é congruente, o que se reconhece facilmente, quando em pensamento o deixamos fazer uma meia volta; pois a contrapartida da contrapartida de um objeto lhe é necessariamente congruente.

Isso deve ser suficiente para compreender a possibilidade de espaços completamente similares e iguais, e mesmo assim incongruentes. Passamos agora ao emprego filosófico desses conceitos. Já é evidente nos exemplos comuns das duas mãos, que a figura de um corpo pode ser completamente similar à figura de outro, e que a grandeza de sua extensão pode ser totalmente igual a de outro, de modo tal que reste, contudo, uma diferença interna, a saber, que a superfície que inclui um não pode encerrar o outro. Visto que essa superfície, que limita o espaço corpóreo de um, não pode servir de limite para o outro, podendo-se rodá-la e virála como se quiser, então essa diferenciação tem de se basear em um fundamento interno. Porém, esse fundamento interno da diferenciação não pode depender do modo distinto de ligação das partes do corpo umas com as outras; pois, como se vê pelo exemplo mencionado, no tocante a isto tudo pode ser completamente idêntico. Não obstante, se imaginamos o primeiro elemento da criação como sendo uma mão humana, então necessariamente teria de ser ou /383/ direita ou esquerda, e para produzi-la seria preciso um ato diferente da causa criadora do que aquele pela qual sua contrapartida pôde ser criada.

Ora, se aceitarmos a concepção de muitos filósofos recentes, principalmente alemães, segundo a qual o espaço consistiria apenas nas relações externas das partes da matéria situadas umas ao lado das outras, então no caso mencionado todo espaço efetivo seria apenas aquele que esta mão ocupa. Visto, porém, que não há nenhuma diferença na relação das partes da mesma entre si, quer ela seja direita ou esquerda, então essa mão seria, no que se refere a essa qualidade, totalmente indeterminada, isto é, ela serviria em ambos os lados do corpo humano, o que é impossível.

Disso fica claro que não são as determinações do espaço conseqüências das posições recíprocas das partes da matéria, mas estas é que são consequiências daquelas, e que também na natureza dos corpos podem ser encontradas diferenças, e de fato verdadeiras diferenças, que dizem respeito unicamente ao espaço absoluto 
e originário, pois apenas por meio dele a relação com as coisas corpóreas é possível; e que, como o espaço absoluto não é um objeto da sensação externa, mas um conceito fundamental, que as torna todas em primeiro lugar possíveis, nós podemos perceber aquilo que na forma de um corpo diz respeito unicamente à relação com o espaço puro somente pela comparação com outros corpos.

Por isso, um leitor reflexivo considerará o conceito de espaço - tal como o geômetra o pensa, e também filósofos sagazes adotaram-no no sistema da ciência natural - não como uma simples quimera, ainda que não faltem dificuldades envolvendo esse conceito, se se quer apreender sua realidade, que é suficientemente intuída pelo sentido interno, por meio de idéias da razão. Mas esse incômodo mostrase por toda parte, se se quer ainda filosofar sobre os primeiros dados de nosso conhecimento, mas ele não é jamais tão decisivo como aquele que se apresenta quando as conseqüências de um conceito adotado contradizem a experiência mais evidente.

\section{Notas}

' $\mathrm{O}$ artigo pode ser dividido em quatro partes:

i) parágrafo $1^{\circ}$ : apresentação dos objetivos do artigo;

ii) parágrafos $2^{\circ}-4^{\circ}$ : apresentação de exemplos de objetos que identificamos e reconhecemos por sua diversa orientação espacial;

iii) parágrafos $5^{\circ}$ e $6^{\circ}$ : definição de contrapartidas incongruentes e apresentação de um método para construí-las;

iv) parágrafos $7^{\circ}-10^{\circ}$ : conseqüências da demonstração para o concepção de espaço.

${ }^{2}$ Leibniz publicou obras importantes nas áreas de direito, história e teologia, mas quase todas sua obra nas áreas de lógica, matemática, epistemologia e metafísica permaneceram inéditas ou apareceram apenas na forma de pequenos ensaios e artigos. Dos trabalhos publicados por Leibniz, apenas a Théodicée (1710) contém uma apresentação sistemática de sua filosofia. Sua obra filosófica mais importante, os Nouveaux essais, só foi publicada postumamente em 1765. As idéias de Leibniz sobre a ars characteristica e a analysis situs, mencionadas por Kant, só existem em forma fragmentária e não-desenvolvida. Ver, por exemplo, o pequeno ensaio "De analysis situs", in C.I. Gerhardt (ed.), Die matematisches Schriften von G.W. Leibniz, vol. 5 (Berlin: Hale, 1849).

${ }^{3}$ Hermanius Boerhaave (1668-1738): Físico, químico, botânico e médico holandês. Kant parece referir-se aqui a Elementa chimiae (1724), vol. 1, p. 2.

${ }^{4}$ Comentário de Walford e Meerbote (1992): “Analysis situs: O projeto leibniziano surgiu de sua insatisfação com a redução cartesiana da geometria à álgebra. A álgebra, insistia Leibniz, era a característica apenas para números ou magnitudes indeterminadas e não poderia expressar diretamente situação, ângulos ou movimento; também estava fadada a 
pressupor os elementos da geometria, de tal modo que as análises que oferecia eram incompletas e insuficientemente radicais. A analysis situs, uma aplicação específica da ars characteristica, foi intencionada como uma forma genuinamente geométrica de análise, expressando diretamente situação, ângulos e movimento. Leibniz distingue nitidamente a analysis situs da análise matemática (a análise de magnitudes, quer determinadas, como na aritmética, quer indeterminadas, como na álgebra). A concepção fundamental da nova análise não seria a de igualdade (definida em termos de mesmas magnitudes) - e portanto sua operação fundamental não seria a equação, como na redução cartesiana da geometria à álgebra - mas a de congruência (ver Gerhardt (ed.) Die matematische Scriften von $G$. W. Leibniz, vol. 2, pp. 20-27), que seria definida em termos de algo poder ou não ocupar o mesmo espaço. Mais tarde, o conceito de congruência daria lugar ao conceito de similaridade (definida em termos de mesma forma ou qualidade). Leibniz escreve: 'Coisas similares são as que não podem ser distinguidas quando observadas isoladamente umas das outras' (Gerhardt (ed.), Die mathematische Schriften von G. W. Leibniz, vol. 5, p. 180; ver também pp. 178-183). As duas relações de congruência e similaridade eram consideradas por Leibniz como derivativos particulares do princípio lógico da identidade ou equivalência. Leibniz estava confiante que a analysis situs, se plenamente desenvolvida (e Leibniz, como Kant acertadamente ressalta, apenas esboçou os contornos de tal investigação) seria capaz não apenas de descrever as características espaciais de figuras, máquinas, plantas, animais e todo tipo de movimento e até mesmo a constituição última da própria matéria, mas também seria capaz de oferecer soluções completas, construções e demonstrações de todas essas propriedades espaciais: todas as configurações seriam reduzidas a seus elementos e princípios últimos. Acima de tudo, Leibniz imaginava a analysis situs como um organon para a ampliação do conhecimento, o que facilitaria, por exemplo, a invenção de novas máquinas. A analysis situs era, assim, concebida como preenchendo uma função tripla: descritiva, explicativa e capaz de servir como um organon. Apesar de Leibniz reconhecer a vasta importância da analysis situs, jamais avançou além dos esboços, que meramente delineiam e ilustram a idéia. Entretanto, pode ser considerada uma precursora da topologia contemporânea (originada no século dezenove com as obras de Riemann, Cantor e Poincaré), que se preocupa não com a forma ou magnitude de configurações, mas com suas qualidades espaciais fundamentais (sua "conetividade"). A concepção fundamental da topologia, como na analysis situs, não é a igualdade (mesma magnitude ou quantidade), mas a congruência (mesma forma ou qualidade: equivalência topológica ou homomorfismo). A relação da analysis situs leibniziana com a geometria é aproximadamente análoga à relação da álgebra com a aritmética. (Não é sem interesse notar que Leibniz, em uma discussão da congruência, afirma de dois triângulos que são efetivamente incongruentes, 'que um pode ser aplicado ou colocado sobre o outro sem alterar nada nas duas figuras exceto seu lugar'. Na verdade, um dos dois tem de ser virado numa terceira dimensão.)" (pp. 458-459, n.4).

${ }^{5}$ Georges-Louis Leclerc Buffon, Comte de (1707-1788): Naturalista francês. Em 1739 foi designado responsável pelo Jardin du Roi e do Musée Royale. Escreveu a Histoire naturelle, générale et particulière (36 vol. Paris, 1740-1788). Segundo Walford e Meerbote (1992, p. 495), ele teria aplicado sistematicamente o princípio leibniziano da continuidade para corroer o conceito de espécies e gêneros rigidamente distintos. Como Bonnet, antecipou a teoria evolucionista. 
${ }^{6}$ Comentário se S. Zac: "O feto, ensina Buffon, desenvolve-se primeiramente no embrião tomando uma forma embrulhada, isto é, uma forma na qual as partes são redobradas umas sobre as outras. Ele as apresenta como um conjunto de 'reduplicaduras'. Mas afirma que é um problema que está acima da geometria ordinária o de determinar as figuras que podem resultar dessas 'reduplicaduras'. Uma ciência matemática, tal como a Analysis situs de Leibniz, poderia nos permitir prever a posição das partes no corpo desenvolvida a partir da posição das partes redobradas no embrião. Mas Buffon afirma que, na realidade, essa ciência ainda não existe. 'Tudo qụe tem relação imediata com a posição falta absolutamente em nossas ciências matemáticas. Essa arte que Leibniz chamava de Analysis situs ainda não nasceu e, entretanto, essa arte, que nos permitiria conhecer as relações de posição entre as coisas, seria também útil e talvez mais necessária às ciências naturais que às artes que não têm senão a grandeza das coisas como objeto; pois tem-se frequientemente mais necessidade de conhecer a forma do que a matéria. Assim, não podemos, quando se nos apresenta uma forma desenvolvida, reconhecer o que ela era antes de seu desenvolvimento; e igualmente quando se vê uma forma embrulhada, isto é, uma forma na qual as partes estão redobradas umas sobre as outras, não podemos julgar o que ela deve produzir por tal ou tal desenvolvimento. Não é evidente que não podemos de modo algum julgar a posição relativa dessas partes redobradas que estão compreendidas em um todo que deve mudar de figura em se desenvolvendo?' (M. C. Buffon, Euvres complètes, t. IV, ch. IX, p. 73. Paris, Imprimerie royale, 1774)." (pp. 131-132, n. 3 bis)

${ }^{7} \mathrm{Na}$ verdade, a analysis situs não tinha por meta - como Kant sugere - a determinação de grandezas ou magnitudes (propriedades quantitativas), mas apenas a descrição e explicação das qualidades ou propriedades formais de objetos espaciais. Um dos objetivos de Kant no artigo é o de mostrar que um teorema central da analysis situs é falso, e que essa falsidade repousa justamente na análise insuficiente de propriedades nãoquantitativas de objetos espaciais.

${ }^{8}$ Essa distinção entre direção [Gegend] e posição [Lage] é fundamental para o argumento de Kant: não se pode determinar a orientação de um objeto apenas pela análise da posição recíproca de suas partes (ver nota 1, (c)). O uso por Kant da expressão "espaço universal absoluto" [absoluten Weltraume] indica aqui uma inclinação newtoniana.

${ }^{9}$ Leonhard Euler (1707-783): Matemático suíço. Eleito para a Academia Real de São Petersburgo (1727) e nomeado sucessivamente para as cadeiras de física (1730) e matemática (1733) na Universidade de São Pertersburgo. Em 1741, foi eleito para a Academia Real da Prússia e passou os vinte e cinco anos subseqüentes em Paris, posteriormente voltando a São Petersburgo. Autor de extensa obra matemática e também filosófica, em particular no que tange ao estudo do espaço e do tempo. Em diversos aspectos, suas concepções anteciparam as de Kant: sustentou que espaço e tempo não podem ser derivados da experiência (apesar de serem reais) e que não podiam ser reduzidos às categorias tradicionais da filosofia. Ver Euler, "Reflexions sur l'espace et le tems" (1748).

${ }^{10} \mathrm{O}$ mesmo exemplo é usado em "Que significa orientar-se no pensamento?" (1786): “... se um dia, por um milagre, todas as constelações guardassem a mesma configuração e precisamente a mesma posição umas em relação às outras, mas a direção delas, que antes era oriental, agora se tornasse ocidental, então na noite estrelada seguinte nenhum olho humano perceberia a menor modificação; e mesmo o astrônomo, se desse simplesmente 
atenção ao que vê, e não simultaneamente ao que sente, ficaria inevitavelmente desorientado." (Ak 8: $134 \mathrm{~s}$.)

"Ver Kant (1786), Metaphysische Anfangsgründe der Naturwissenschaft (Ak 4: 483 s.).

${ }^{12}$ Edme Mariotte (ca. 1620-1684): Cientista francês. Um dos primeiros membros da Academia de Ciências de Paris, para a qual publicou artigos sobre uma ampla variedade de assuntos. Ver De la nature de l'air. In: CEuvres de Mariotte (1717), vol. 1, pp. 160 s.

${ }^{13}$ Don Antonio de Ulloa (1716-1795): Oficial superior da marinha espanhola, membro da Sociedade Real. Ver Relación historica del viage a la America meridional (Madrid, 1748).

${ }^{14}$ Giovanni Afonso Borelli (1608-1679): Astrônomo, matemático e biólogo italiano, conhecido por sua teoria corpuscular e sua teoria física dos satélites de Júpiter. Publicou um estudo sobre as capacidades relativas dos olhos direitos e esquerdos: "Des Herrn Alphonsus Borelli Bemerkungen von der ungleichen Stärke der Augen, woraus man schliessen kann, dass das linke Auge die Objecte gemeiniglich viel deutlicher sehe als das rechte", Hamburger Magazin, Bd. XXIII, 1759, pp. 641-645. (Tradução alemã de: J. B. Denis, Recueil des mémoires et conférences sur les arts et les sciences présentées à Monseigneur le Dauphin pendant l'année 1672. Amsterdam, 1673. pp. 295-298).

${ }^{15}$ Charles Bonnet (1720-1793): Naturalista suíço. Kant pode estar referindo-se ao Esssai de psychologie (London, 1754) ou ao Essai analytique des facultés de l'âme (Copenhagen, 1760).

16 "Iguais e similares" [gleich und ähnlich] é uma expressão técnica nesse contexto. Iguais são objetos que possuem a mesma grandeza ou magnitude (duas linhas são iguais se possuem o mesmo comprimento, dois ângulos são iguais se possuem a mesma abertura, duas figuras são iguais se possuem a mesma área etc.); trata-se, portanto, de uma noção quantitativa, e expressa algo só pode ser aprendido comparativamente à grandeza ou magnitude de outros objetos. Similares são objetos que possuem a mesma forma e estrutura (duas retas, dois círculos, dois cubos etc. são entre si similares independentemente de seus tamanhos); trata-se, nesse caso, de uma noção qualitativa, que expressa algo que pode ser apreendido independentemente de qualquer comparação. Um dos teoremas centrais visados por Leibniz no seu projeto de uma analysis situs é o de que quaisquer objetos iguais e similares são congruentes, isto é, podem ser movidos de tal modo a sucessivamente ocupar o mesmo espaço. As contrapartidas incongruentes fornecem um contra-exemplo a essa tese (pois são iguais, similares mas incongruentes). Kant pretende com esse contra-exemplo não apenas pôr em xeque a analysis situs, mas toda a concepção leibniziana do espaço.

${ }^{17}$ Contrapartidas incongruentes também são discutidas por Kant na Metaphysik Herder (1763, Ak 28: 15), na Dissertação de 1770, § 15 (Ak 2: 402 s.), nos Prolegomenos, $\S 13$ (1783, Ak 4: 285 s.), nos Metaphysische Anfangsgründe der Naturwissenschaft (1786, Ak 4: 483 s.) e em “Que significa orientar-se no pensamento?” (1786, Ak 8: 134 s.). 